\title{
It's Academic
}

\section{Shelf-Ready Standing Orders at the University of Florida's Smathers Library}

\section{Michele Crump and Steven Carrico}

The University of Florida Smathers Library receives many of its domestic serial standing orders from the Academic Book Center of Portland, Oregon. In February 1998, the two organizations agreed to begin an outsourcing project in which the Academic Book Center would supply the library with a large percentage of these standing orders with complete physical processing. After three years of receiving shelf-ready standing orders and monitoring a low error-rate and overall improvement in workflow efficiency, library administration declared the outsourcing project a success.

Tn fall 1995, the University of Florida Smathers Library underwent a full-scale I restoration without moving staff and materials out of the building. This environmental situation forced library staff to deal with the many inconveniences associated with a multimillion-dollar building renovation. The largest department in the building is the Resource Services department, which was created by merging the former Acquisitions and Cataloging Departments. Since large amounts of materials are routinely routed through the Resource Services department, the renovation project adversely affected established workflow. The approval review shelves were situated on the third floor of the Smathers Library and the building's elevator was out of operation for several months, which resulted in a major inconvenience for the Resource Services department staff handling domestic-approval monographs. To keep the incoming material on the ground floor and restrict the handling of that material, Resource Services and Collection Management agreed to receive domestic-approval monographs shelf-ready for the duration of the renovation project.

In addition to accepting domestic approvals shelf-ready, Smathers Library implemented an outsourcing project with Yankee Book Peddler (YBP) to receive all domestic monograph firm orders with both catalog records and shelf-ready processing. Although the decision to temporarily outsource physical processing for both the domestic-approval monographs and firm orders was made more or less out of necessity, the unforeseen benefits that surfaced with the implementation of the shelf-ready operation became obvious to the library. Outsourcing the physical processing for domestic-approval monographs and firm orders increased the speed and efficiency of entering domestic monographs into the collections, and it saved valuable staff time that could be used for other cataloging activities. Pleased with this success after only a few months of the project, library administration elected to retain the physical processing service from YBP on a permanent basis for the firm-order monographs.

The shelf-ready processing contract with YBP included applying call number labels, 3M tattle-tape, property and location stamps, and barcodes. In addition, as 
part of the contract, when Library of Congress catalog records were available through LC MARC tapes, YBP supplied MARC records for file transfer into NOTIS. For these processing services, YBP charged the Smathers Library $\$ 2.08$ per monograph piece to reimburse YBP for the costs encumbered in supplying the physical processing and catalog records. Each piece in a multivolume set cost $\$ 2.08$ to process regardless of the fact that a set would require only one catalog record. Library administration considered this cost reasonable even though a 1995 study by the library's preservation department (at the time the department responsible for processing) showed that physical processing cost the library only $\$ 1.58$ per monograph. Paying YBP an additional $\$ .50$ per item was deemed cost efficient when viewed in the "big picture" of library processing workflow. With processing time cut by more than $50 \%$, domestic monographs were now on the shelf and ready for patron use within one week of receipt. In the study's conclusion, the researchers stated that "the overall decrease in physical processing is significant enough for staff in the processing area to contribute more time to preservation, scanning and digitizing projects" (Crump 1996).

The increased cost was not a deterrent because the Resource Services department valued the savings in staff time more after weighing price against benefits to the library and its patrons. For that reason, the library seized the opportunity to redirect workloads and offer staff opportunities that would enhance job skills; the advantages to staff and patrons and the reduction of workloads was well worth the extra $\$ .50$ cost per processed item. Concurrently, the library performed a cost analysis comparing OCLC PromptCat program and LC MARC tape loading procedures, and decided that it would be more cost effective to import LC MARC tape monograph records supplied from the vendor rather than to receive cataloging records through the OCLC PromptCat program. The YBP project set the stage for instituting similar outsourcing projects in the library and the cost assessment established a price benchmark for evaluating the value of comparable projects.

Throughout the development of the YBP shelf-ready programs, library staff reviewed the acquisitions and cataloging systems in place and made organizational and business changes to promote further efficiency in the workflow. During this evaluation and adjustment of workflow time, Resource Services staff noted similarities in the monograph firm order workflow and that of the serials standing order workflow. If this workflow model was successful for monographs receipt, could it be applied to serials standing orders operations with the same success and benefits to staff, the library, and its patrons? Late in the fiscal year of 1996, Smathers Library decided to pursue this question and began discussing the idea with Academic Book Center (ABC), now a Blackwell Company, of starting a shelf-ready project for the domestic standing orders supplied by the vendor.
Several meetings and e-mail discussions took place, and the operations at each business were examined to identify the potential benefits a shelf-ready project could provide to both $\mathrm{ABC}$ and the Smathers Library.

\section{Literature Search}

In the process of this project, a number of studies and reports from librarians and vendors on standing orders and outsourcing of both cataloging and physical processing tasks were consulted. Buell and Bueter, in a report from a workshop given at the 1993 NASIG Conference, define standing orders as "non-periodical serials" and cite examples: "annuals, yearbooks, almanacs, multi-volume sets, non-monographic serials with volume numbers, numbered and unnumbered monographic series with individual titles, supplements, and conference proceedings" (Buell and Bueter 1994, 203). They discuss the difficulties inherent in handling standing orders, list the pros and cons of consolidating standing orders with a vendor, and review the vendor's responsibilities in providing standing orders to a library.

Hogan observed that the majority of standing orders correspond to one of five categories-annuals, analyzed serials, sets, analyzed sets, and series-but admitted that some standing orders do not fall under any of these categories; he referred to these as "Exotic Fauna." He noted that standing orders are difficult to manage and track because "the handling of standing orders combines both book and serial processing routines, sometimes simultaneously" (Hogan 1994, 96-97).

Winters and Hirshon (1996), using their experiences from developing requests for purchases (RFPs) and vendor contracts in two academic libraries, analyzed the steps a library should take during the outsourcing process. Their guide, "Outsourcing Library Technical Services: A How-ToDo-It Manual for Librarians," covers how to determine whether a library should outsource its technical services, the development of requests for purchases (RFPs), and the outsourcing of books, serials, and cataloging. It also offers methods to evaluate outsourcing and the effect outsourcing has on library staff.

In a similar spirit of offering aid in developing an outsourcing plan, Joy and Lugg (1998) presented "The Books are Shelf-Ready; Are You?" They addressed both the library and vendor viewpoints on establishing a shelf-ready plan and outsourcing the physical processing functions of library materials. Joy, a collection manager at the University of Vermont, and Lugg, a vice president at YBP, collaborated to establish a shelf-ready service for approval books at the University of Vermont. The authors presented the library and vendor perspectives on developing and using shelfready service by putting together a series of commonly 
asked questions on the issue of outsourcing cataloging and physical processing. These questions open a valuable dialogue for libraries planning to institute shelf-ready vendor services, and urge libraries to examine their current workflow and carefully review the potential benefits and possible obstacles they will face during the process of starting and fine-tuning a shelf-ready program. The authors particularly stress the need for good communications between the library and the vendor and between the various departments within the library. Finally, they offer a checklist of "sage advice" libraries can use as they consider and begin outsourcing.

Bénaud and Bordeianu (1998) submitted a thorough and comprehensive review of outsourcing in Outsourcing Library Operations in Academic Libraries: An Overview of Issues and Outcomes. They review the reasons for the popularity of outsourcing in libraries and examine the debate surrounding the operation. The authors also study outsourcing in collection development, acquisitions, serials, cataloging, and preservation. Throughout the work Bénaud and Bordeianu focus their attention on academic libraries and even include survey results compiled from the responses of 109 Association of Research Libraries (ARL) and 110 medium-sized academic libraries.

Propas and Johnson (1998) described how Stanford University libraries instituted quality control programs for approval-plan books arriving with vendor-supplied cataloging. They also illustrated how the staff of the Serials and Acquisitions department assisted in developing the collection development profiles used by the vendor. The quality control programs they included offer helpful guidelines for monitoring both the cataloging records and the physical processing of the books.

\section{Setting up the Profile}

As the literature on the subject reveals, working through an implementation plan for extended service such as shelf-ready processing builds the partnership between library and vendor. The meetings and discussions offer an opportunity for understanding the workflow of each operation and provide venues for negotiating services the library desires and the products the vendor can supply. Serials staff of the Resource Services department decided that only annual publications and series classed together/analyzed would receive physical processing, as the call numbers remain constant for these categories of serials. The serials staff performs all serials ordering, receiving, binding, and cataloging activities for almost all the serial standing orders. Monographic series that are either classed together or classed separately/analyzed receive copy cataloging by the serials staff when catalog records are available. If original cataloging, subject analysis, or call number assignment is needed, the material is distributed to the cataloging sections.

$\mathrm{ABC}$ has been the Smathers Library's primary domestic standing order vendor since 1993, supplying $18 \%$ of the total number of standing orders the library receives (figure 1). After preliminary discussions, ABC agreed to work through the project with the library although it would have to manually produce each customized call number label. At the time, ABC's computer system did not have the capability to store all the call number variations that various library customers could assign to the same serial title. The profile set up was labor intensive for both organizations (figure 2). ABC provided a report of the library's account, listing all the titles Smathers Library received from them on standing order. The acquisitions and cataloging record for each title was found in the library's integrated system, NOTIS, to determine the cataloging treatment. When the title was identified as a serial annual or a classed together/analyzed series, the title list was annotated with the call number and indicated the correct line format for the established classification number and the volume enumeration. Titles with classed separately/analyzed treatment were eliminated from the project at this time because of call number variation that is not easily predictable for handling in that workflow. As noted earlier, the Resource Services department had established specifications for the physical processing with YBP.
Serials budget:
$\$ 3,359,457$
$53 \%$ of total materials budget
Standing orders budget (domestic and foreign):
$\$ 350,400 \quad 10 \%$ of total serials budget
Standing orders with Academic Book Center: $\$ 61,384$
$18 \%$ of total standing order budget

Figure 1. Serials and Standing Orders Budgets, 1999-2000

1. The vendor will supply and affix one $3 \mathrm{M}$ tattle-tape to each piece.

2. The vendor will attach a barcode label to the back cover of each piece.

3. The vendor will apply a property stamp on either the top book edge or bottom of title page.

4. The vendor will apply library location stamps to each piece.

5. The vendor will apply call numbers and proper enumeration to each piece.

6. The library will supply the vendor barcodes and stamps; the library will also provide the vendor with the call numbers and sample enumeration sequences to use.

7. The vendor will charge $\$ 2.00$ per piece for processing.

Figure 2. Profile and Set-up Agreement 
Following the YBP model, the physical processing received from $\mathrm{ABC}$ includes affixing the barcodes, inserting the tattle-tape, stamping the property and location, and attaching the call number spine label. As part of the agreement, the library supplies $\mathrm{ABC}$ with library property and location stamps and barcode labels.

At the beginning of the project, Smathers Library was receiving 671 domestic standing order serial titles from ABC. Of these standing orders, 593 fell under the categories of annuals, directories, handbooks, proceedings, almanacs, yearbooks, or classed together/analyzed serials. Since the call numbers and holdings locations remain constant for these standing orders, electing to outsource the physical processing for these serials was an easy choice. The remaining 78 standing orders did not receive physical processing at $\mathrm{ABC}$, as series that are classed separately/analyzed and processing can not occur until the items receive subject classification analysis. As a result of this outsourcing project with $\mathrm{ABC}$, more than $88 \%$ of the domestic serials standing orders received by the Smathers Library arrive shelf-ready.

$\mathrm{ABC}$ receives standing order titles from publishers throughout the week. Each title receives physical processing according to the specifications based on whether it is an annual or a classed together/analyzed series. ABC performs physical processing on the determined serials, then boxes, invoices, and ships the serials to Smathers Library according to their shipping schedule. At the request of Smathers Library, ABC issues separate invoices for the standing order items and physical processing because the library maintains unique fund accounts for each service to ensure accurate audit trails for the State of Florida.

\section{Monitoring the Standing Orders and Physical Processing Costs}

In February 1998, the library received its first shipment of processed serials from $\mathrm{ABC}$. To monitor the quality of physical processing, one serials staff member is assigned to receive and review the $\mathrm{ABC}$ shipments. That staff member opens the boxes and compares the contents of each box against the enclosed invoice. The processed material, identifiable because of the call number affixed on the spine, is separated from the serials received without processing. Once the material in a shipment has had this initial inspection, a serials staff member distributes the material received without physical processing to staff for receipt and payment in NOTIS and for cataloging when appropriate. The processed material is inspected to ensure that the call number labels, barcodes, and location and property stamps are placed correctly on the book. Serials received with physical processing are received and paid for in NOTIS and then copy cataloged when appropriate. Statistics are kept on the number of titles received with processing and reported on a monthly basis for cost analysis.

\section{Problems Encountered and Reducing the Error Rate}

Twice serials staff conducted three-month-long quality control studies. The first study was undertaken on June 1, 1998, four months after the shelf-ready project had begun. The second study was launched on December 1, 1999, almost two years from the beginning of the project. Examining the statistics kept during the two studies shows a steady decline in the percentage of errors found by the serials staff handling the standing order materials supplied by ABC (table 1).

The majority of problems encountered by the serials staff were for the most part small and easily corrected. The early errors detected were either in the call number enumeration-for example, omitting the volume number or year of publication - in the holdings locations, or with serial title changes. At the end of the first study, the serials staff calculated ABC's error rate at approximately $13.5 \%$ for all processed standing orders. Errors were listed with title, NOTIS record number, and a short description of the problem; after several errors had been detected and batched together, serials staff e-mailed ABC personnel in charge of handling the standing orders. Based on back-and-forth email communications throughout this time, ABC staff became more familiar with Smathers Library's call-number format and the location stamps, so not surprisingly the error rate steadily declined. By the end of the second study, almost a year and a half after the first study, the error rate had dropped to a little more than $8.5 \%$.

The staff at Smathers Library and ABC experienced a learning process on both ends: the library serials staff had to effectively communicate the particular processing needs for each standing order and to monitor the incoming materials for mislabeled items; for the staff at $\mathrm{ABC}$, the challenge was to organize and manage physical processing for hundreds of standing orders. The staff at ABC certainly met this challenge and is now contracting with at least four other academic libraries for shelf-ready standing order services.
Table 1 Vendor Performance Studies

\begin{tabular}{lcccccc}
\hline & & & \multicolumn{3}{c}{ Type of Errors } \\
Period Monitored & No. Vols. Rec'd & No. Errors & $\%$ Errors & Call No. T/C & Loc. \\
June 1-Aug. 31, 1998 & 119 & 16 & .1345 & 11 & 3 & 2 \\
Dec. 1, 1999-Feb. 29, 2000 & 140 & 12 & .0857 & 6 & 4 & 2 \\
\hline
\end{tabular}


Serial title changes are an ongoing obstacle when receiving shelf-ready continuations, as they often involve complications and always require communication between $\mathrm{ABC}$ standing order department and serials staff. Serial title changes can be messy, convoluted, and create receipt problems. For example, a serial title change can require a call number change, which necessitates that both $\mathrm{ABC}$ and serials staff be aware of the change and alter their records accordingly. Serial titles can combine, split into two distinct titles, or cease publication altogether; in each of these cases, library and vendor staff must act to upgrade their records. Indeed, even a simple title change requires prompt and accurate communication between $\mathrm{ABC}$ and Smathers Library. When NOTIS records are updated with new title information, the new title and its NOTIS record number must be reported to $\mathrm{ABC}$ so that the same information appears in both systems correctly. Fortunately, serial title changes do not seem to occur frequently with standing orders so this has not become a big problem for either organization.

\section{Adding Monographic Classed Separately Series and MARCIVE Records}

After a year of receiving series titles with physical processing from $\mathrm{ABC}$, the library decided to follow the YBP approval and firm order shelf-ready example and extend the $\mathrm{ABC}$ project to include the receipt of catalog records for classed separately/analyzed serial standing orders. The specifications were broadened to implement a workflow similar to that of the YBP approval program. ABC searches and orders monographic catalog records for the classed separately/analyzed titles through the MARCIVE service (only monograph records, no serials, are to be selected or sent from MARCIVE). If a record cannot be found, $\mathrm{ABC}$ supplies the title unprocessed. If the appropriate catalog record is found, $\mathrm{ABC}$ applies the call number as it appears in the catalog record and completes the processing. $\mathrm{ABC}$ then orders the catalog record from MARCIVE, and MARCIVE creates a file of the selected records, which is downloaded into Smathers Library's NOTIS system.

Serials staff pick up the FTP file from MARCIVE once they are notified via e-mail that the file is ready. They run the file through MARCon, a file converter program created by Smathers Library's Systems Office, which converts MARC records by adding indexing fields that will load into NOTIS. The MARCon program batches records in a load file and, at the same time, identifies problem records and moves them into a separate file. Upper-level staff trained in resolving loading-type questions analyze the problem file, resolve the errors, and either rerun the titles through the program or complete the record load by manually adding the titles to NOTIS.
In order to load the MARCon output file into NOTIS, serials staff use FULoad, a software program developed by Gary Strawn at Northwestern University for Smathers Library. FULoad downloads the MARCIVE records to NOTIS and writes a problem titles file that can be reviewed and handled separately similar to the error file MARCon creates. At this point, staff scan and remove duplicate records. Currently, 35 standing order titles have been received in the Resource Services department in this fashion since June 1999. It is expected that the number will increase over time as we add other categories of standingorder material.

The library is now considering adding classed together/analyzed monographic series to the MARCIVE record receiving process. Because the call number for this category of material is fixed, the physical processing workflow would remain unchanged. Library staff would receive the monographic records for titles $\mathrm{ABC}$ located in MARCIVE, but ABC staff would know not to apply the MARCIVE record call number to any titles identified as classed together/analyzed; rather, the class number Smathers Library supplied the vendor would be applied to the book. At present, the library receives only 14 classed together/analyzed monographic series on standing order from $\mathrm{ABC}$, and within those 14 series approximately 25 items are received per year. Although the number of items and their corresponding catalog records is few when compared to everyday workflow, any reduction in processing time that results in making materials available to patrons sooner is viewed as a plus. Staff also benefit from this time saving as they apply their talents to other library projects and develop new skills in the process.

\section{Conclusion}

Since the beginning of the contract with $\mathrm{ABC}$, Smathers Library has received more than 1,120 serials with physical processing. During the fiscal year 1997-98, in five months the library received 293 standing orders with physical processing at a total cost of $\$ 586$. In 1998-99, the library received 601 shelf-ready serials at a total cost of $\$ 1,202$; in fiscal year 1999-2000, the library received 650 shelf-ready serials at a cost of $\$ 1,300$. Overall, in the two and one-half

Table 2. Volumes Received/Processing Costs of the ABC ShelfReady Project

\begin{tabular}{lrr}
\hline Fiscal Year & Volumes Received & Processing Costs \\
$1997-98$ & 293 & $\$ 586$ \\
$1998-99$ & 601 & 1,202 \\
$1999-2000$ & 650 & 1,300 \\
Total & 1,544 & $\$ 3,088$ \\
\hline
\end{tabular}


years of the project, 1,544 items have been received, processed, and more efficiently added to the library's holdings as a result of the contract with $\mathrm{ABC}$ (table 2). To ensure the effectiveness of the project, serials staff will continue to monitor the account by annually taking inventory of the titles and updating the library and ABC's records to reflect current order status and accurate processing instructions.

When the library administration first thought about adopting the shelf-ready workflow for domestic standing orders, the benefits of getting the materials on the library's shelves in record time was already being realized with the YBP project. This was the first priority we wanted to achieve in the outsourcing project, but the library administration also recognized that another benefit of the project might be that it would open development opportunities for staff. To a significant degree, both goals have been achieved. The standing-order materials are getting through the system and on the shelves faster, which pleases the patrons; meanwhile, receiving materials shelf-ready has dramatically cut staff time devoted to physical processing, allowing staff to redirect their expertise and concentrate on assignments important to the library's future.

In the article "Approval Plans and Approval Vendor Selection in an Outsourcing Environment," Schatz and Baldwin (1998) said this about the outsourcing process in general and approval plans specifically: "Today's era of selling in an outsourcing environment is what I'd like to call the era of collaborative selling. In the library world of today, the approval plan decision likely involves associated decisions about cataloging, book processing, and OPAC enhancement. The approval plan not only represents a means of obtaining important new works but is also viewed as a means of improving internal staffing and workflows." Successful outsourcing in this "era of collaboration" requires clear communication between vendor and library, particularly if a shelf-ready program is large and ongoing. It builds a part- nership environment in which development of outsourcing services becomes a mutual endeavor. Both organizations gain advantages as they re-examine their internal operations and establish innovative programs and workflows that other libraries can use. Like the project described in this article, the process of improving workflow and efficiency should remain a constant practice. The library should examine continually the way it acquires and processes materials, always keeping in mind that the key motive for instituting changes is to make information in all its forms more readily accessible to library patrons.

\section{Works Cited}

Bénaud, Claire-Lise, and Sever Bordeianu. 1998. Outsourcing library operations in academic libraries: An overview of issues and outcomes. Englewood, Colo.: Libraries Unlimited.

Buell, Vivian, and Rita VanAssche Bueter. 1994. Standing orders: The serialist's stepchild. The Serials Librarian 24 (3-4): 203.

Crump, Michele. 1996. Shelf ready summary report. University of Florida, George A. Smathers Libraries, Resource Services Department. Accessed Nov. 10, 2000, http://web.uflib.ufl.edu/ $\mathrm{rs} / \mathrm{rsd} /$ shelfrpt.html.

Hirshon, Arnold, and Barbara Winters. 1996. Outsourcing library technical services: A how-to-do-it manual for librarians. New York: Neal-Schuman.

Hogan, Walter P. 1994. Standing order matrices; or, only a mother could love a non-periodical continuation. In Management and organization of the acquisitions department, ed. Twyla Racz and Rosina Tammany. New York: Haworth.

Joy, Albert, and Rick Lugg. 1998. The books are shelf-ready; are you? Library Acquisitions: Practice \& Theory 22 (1): 71-89.

Propas, Sharon W., and Sue-Ellen Johnson. 1998. Outsourcing, quality control, and the acquisitions professional. Library Acquisitions: Practice \& Theory 22 (3): 279-85.

Schatz, Bob, and James A. Baldwin. 1998. Approval plans and approval vendor selection in an outsourcing environment. Library Acquisitions: Practice \& Theory 22 (4): 423-29. 